\title{
ANALYSIS OF AN INDOOR POSITIONING SYSTEMS ${ }^{4}$
}

\begin{abstract}
Recently, due to advances in the development of various technologies which can be used for locating, it is possible to develop systems which include software solutions for the user locationing and guidance in the interior, closed or covered areas where the existing location technologies and systems for locating and guidance applicable at open, outdoor areas cannot be used. This paper analyses the available hardware, software and network technologies which can be used for creating a positioning system for interior, closed or covered area. The paper analyses technologies which can be used in such distributed systems for the implementation of functionalities that are needed or required in the Indoor Positioning System (IPS). The paper describes the concept of the IPS system. It presents the IPS systems available on the market. It shows the technologies that can be used to implement the IPS system and the analyses of categories which affect the IPS system implementation. The paper demonstrates that none of the technologies analysed meet all of the observed categories while the BLE technology achieves the most favourable results in individual categories.
\end{abstract}

Key words: IPS, indoor positioning

\section{INTRODUCTION}

Indoor Positioning System (IPS 5 ) is a system of network connected devices which is used for wireless locationing of objects and persons inside buildings and partly covered areas (Lemmens, 2013.). Technologies used by those systems become commercially available in various forms (required hardware) and with various characteristics (functionality by means of visual contact, radio-frequency, magnetic field, sound). There is a large number of available technologies that can be used in the IPS system.

Outdoor positioning systems usually use satellite technologies (eg. GPS 6 ) or network technologies (determining a location at the base station of the mobile service provider, Wi-Fi). GPS technology

\footnotetext{
PhD, Senior Lecturer, Polytechnic of Rijeka, Vukovarska 58, 51000 Rijeka, Croatia. E-mail: mkaluza@veleri.hr Student, Polytechnic of Rijeka, Vukovarska 58, 51000 Rijeka, Croatia. E-mail: kbeg@veleri.hr MSc, Senior Lecturer, Polytechnic of Rijeka, Vukovarska 58, 51000 Rijeka, Croatia.E-mail: bvukelic@veleri.hr Received: 15 February 2017; Accepted: 1 April 2017

IPS (Indoor Positioning System)

GPS (Global Positioning System) is a system for determining a position on the ground.

Wi-Fi is a standard for a wireless network
} 
has become widely available in the late 1990's and has significantly improved the outdoor positioning system. Today, smart devices (smartphones, tablets, tracking devices, watches) often have a built-in GPS component.

There is a need for locating in the interior area. Satellite positioning has not been functioning in closed areas, therefore it has led to the emergence of new technologies to make such a positioning possible. Indoor positioning is more complex than the outdoor positioning (by means of GPS) as the implementation of technologies used indoors may require some additional infrastructure. IPS could be designed to search for items or groups of items in the supermarket, to find the appropriate office within the building of an institution, to orient oneself within the hospital complex, to find certain stores within the mall, to get around easily at the airport, museum, etc.

What technologies are available for developing IPS, what are their possibilities? For what IPS possibilities can available technologies be used? What functions does the indoor positioning system execute or control?

The aim of the paper is to show which technology can be used as the basic technology for the IPS to achieve the best characteristics (functionalities) of the IPS.

The paper describes some IPS functionalities, and examples of IPSs available on the market. Also describes technologies that can be used in IPS. The paper represents an analyses of some characteristics of IPS (and technologies that can be used in IPS): battery life, location accuracy, maintenance, system security, installation, maintenance costs, push notifications, blue dot navigation and signal sensitivity. The analyses can be used for the starting point of the selection of technologies for the IPS implementation.

\section{IPS FUNCTIONALITIES AND EXAMPLES}

Technologies used for indoor positioning vary in accuracy, cost of implementation and installation and maintenance activities.

IPS system is composed of three distinct elements (Senion, 2016):

- a dynamic platform of the positioning system,

- location devices or signal transmitters,

- a mobile application that retrieves and interprets signals.

Indoor positioning system constantly operates in order to determine the exact location of the device. The coordinates (latitude, longitude, and height / number of floors) are the output of such operation. In order for the coordinates to be applicable, they need context, that is, a map (Senion, 2016). Basically, a technology that allows obtaining information on the location of objects within the building results in the following two concepts: knowing when the user is located near a certain point, or being able to determine the position of the user regardless of their location in the building. The first refers to a system based on proximity (PS ${ }^{8}$ ) and the other is the IPS system (Senion, 2016).

8 PS (Proximity System) 
PS uses location devices that operate with Bluetooth ${ }^{9}$ low energy $\left(\mathrm{BLE}^{10}\right)$ and it acts as transmitters that broadcast their identification data to nearby smart mobile devices.

The PS is used for the purpose of finding the user's location (people and things) in certain moments. The location device provides information on the time when a person or thing is located within a range of a certain point, that is, of a location device. This information can be used to "target" customer located near a shop and for sending notifications.

The lack of such a system is the range of transmission. If the implementation of the PS is aimed at achieving greater connectivity with the user, it is necessary to set up location devices at various locations within the building. These location devices can also be a subset of an IPS (Törnqvist, 2017).

IPS includes a location device as part of a larger system that enables other functionalities for applications: route search, search for friends, enhanced marketing opportunities, detailed analytics.

IPS uses multiple signals from location devices, as well as motion sensors and other sensors on the user's smart mobile device. By combining these elements, the IPS can accurately calculate the position of the user. Some IPS systems include analytical processes of the system's basic data and data created during system operation. Such processes can predict the future movement of the user even in buildings with multiple floors.

When searching for a route, the IPS system functions in the same way as the GPS for outdoor positioning. Instead of retrieving the satellite signal, the IPS exchanges signals between the location devices and smart devices' sensors. The functionality of a route search helps a user to manoeuvre in the area, such as a shopping centre or hospital. The guidance, as well as the prediction of the user's movement, arebased on the current route. Locating friends works in the same way, allowing users to find each other indoors.

IPS also helps to ensure marketing opportunities. For example, a shopping mall can define arbitrary areas where they want to display information or provide commercial advertisements. Areas can be installed and defined within the IPS system without the need for moving the hardware responsible for sending notifications to customers.

IPS can also provide detailed analysis, even in real time, display user's movement in the building and enable a user to make decisions. From such analysis it is possible to see which zones in a shopping mall are more frequently visited.. IPS also enables the analysis of customer behaviour, for example, which shops are the most visited, which shop the customer has just passed by and what is his/her route, and even whether the customer has stopped in front of a shop window and in front of which shop window exactly.

\footnotetext{
9 Bluetooth is a short-range wireless technology that enables wireless data communication between digital devices such as computer and digital camera - URL: https://www.sony.ru/support/emanual/SRS-X55/HR/contents/ TP0000629089.html

10 BLE (Bluetooth Low Energy) is a Bluetooth technology that uses less energy
} 
IPS is also applied at the health care institutions. The system can guide the patient to the office of a specific doctor. Another use of the IPS system in health care involves the use of location devices for medical equipment in order to locate certain equipment more easily, which is particularly useful in emergency cases.

The main difference in the functions of the IPS in relation to the PS is in the fact that the IPS collects data on the movement of the user first and then it can analyse the traffic at certain parts of the system, while for the PS system it is necessary to already know in advance which parts of the system should be analysed in order to timely place the location devices on the desired position (Törnqvist, 2017).

The Wi-Fi technology was used at the very beginning of the indoor positioning. However, since it was not intended to be used for the purpose of positioning, the positioning was not precise enough and there was also a lot of collaboration between the phone and the network itself (Meridian, 2017).

In Meridian company, at the time, one of their first projects was creating a mobile app for a large and famous museum. The museum was using one of the very first indoor location systems and it operated by measuring Wi-Fi signals to compute user location. These signals tended to fluctuate dramatically and the location quality was very poor as a result. In the museum's app, the "blue dot" would float wildly around, jumping 30 feet at a time, and it felt very unreliable (Meridian, 2017).

"Blue dot" represents the user's movement in the area and it also enhances the user experience. When the user moves through the room the "blue dot" should move smoothly and also be as accurate as possible regarding the user real position. It is equivalent of the real-time location recognition as GPS is in the outdoors.

The "blue dot" was not only showing the movement of the user incorrectly, but it also appeared randomly on the screen. To improve the accuracy of the positioning, the algorithm that would allow this improvement was enhanced. At the same time, the user experience, that is "the blue dot experience" was also worked on, in order to accurately display the user's movements. The user's movement from one room to another was also enhanced, without taking into account small intermediate steps meaning Meridian redesigned the entire app experience around the assumption that the user location just was not going to be precise. They focused the "getting directions" experience around going from one big hall full of exhibits to another instead of all small steps that the user takes to get there. The hall exits are perfectly well-marked in the space and the user just needs to know which one is next (Meridian, 2017).

In most cases, the Wi-Fi component is already supported or even included on users' smart devices, and the buildings can be adequately equipped with the appropriate infrastructure. Sometimes, counters need to be installed at the entrance area, as well as a video camera at specific locations in order to analyse the user's movement by recording the user's locations.

A mobile application guides the user to certain services and products and also displays notifications and targeted marketing ads. 
An administrative interface, the so-called dashboard, may be positioned at the central site, and thus manages the system (updating locations, managing alerts, etc.).

Backend software contains the following components (Mattsson, 2014):

- $\quad$ system for running location-based alerts,

- analytical system based on movement of the user,

- database containing location information,

- management and security layers to protect data (Administrative Tools),

- integration into existing systems, for example, e-commerce, marketing automation, POS ${ }^{11}$, content management,

- $\quad \mathrm{API}^{12}$ to import and export data and location-based triggers.

Certain examples of the IPS system are presented below.

\section{1 Senion}

"Senion AB" is a company in Sweden that has developed an IPS called Steplnside. Apart from user instructions on how to locate a specific place in form of tabs, this system also offers some additional options: reports on the movement of people who use the system, information about how many users have visited a particular area at a particular time. It also offers notifications to customers on the basis of virtual zones in the area where they are located. It is also possible to determine the points of interests of users and provide them with dynamic navigation experience (Senion, 2017).

The system uses https / AES 128-bit encryption to ensure the integrity and protect against unwanted users' "intrusion" on the background software components, encrypted identifiers of location devices and continuous performance and user activities monitoring (Senion, 2017-2).

The technology used by this IPS has not been explicitly mentioned. Some sources indicate the use of public Wi-Fi system (Senion, 2015, 2015-2), some point to the use of location devices that use BLE technology (beacons - sensors that transmit a BLE signal (Senion, 2015-3). Senion website mentions that the company uses a technology using advanced sensors which provide the exact location of the device with the help of fusion algorithm and smartphone motion and radio sensors (Senion-4, 2015). The use of those technologies for achieving additional functions of the system, e.g. analysis of the area and movement of users, management of BLE transmitters, user interaction with points of interest, user interaction with the specified zones in the building have also been mentioned (Senion-4, 2015). Beacon Management System is used for locating all the location devices and for their maintenance (Senion-4, 2016).

\footnotetext{
POS means a Point of Sale - URL: http://www.posmatic.com/point-of-sale/what-is-point-of-sale.php API means Application Programming Interface - URL: http://laris.fesb.hr/java/paketi.htm
} 


\subsection{Infsoft}

German company "INFSOFT GmbH" offers indoor navigation, indoor analytics, monitoring and location services since 2006 (Infsoft, 2016). This IPS uses location nodes, location identifiers, UWB ${ }^{13}$ (Infsoft, 2016), Wi-Fi and beacon devices for indoor positioning. Apart from the development of all-in-one solution for large customers, scalable and SDK ${ }^{14}$ packages are also in offer.

It allows client-based and server-based positioning. With the client-based positioning (the client usually being a smart device), a navigation service is used and the use of the application is also required. The technologies used are Wi-Fi networks that provide user location with 5-15 meters accuracy or BLE transmitters whose radio transmitter emits signals used by the application to calculate the position with 1-3 meters accuracy. Regarding the server-based positioning, a method that does not require the application is used, however, this type of positioning cannot achieve communication with the user. The method is used to locate objects and people, or when generating analysis on the movement of the user. This IPS uses its own developed location nodes that detect all smart devices that are able to receive $\mathrm{Wi}-\mathrm{Fi}$ signals and BLE transmitters; location codes that are similar to nodes, more flexible and more suitable for monitoring several buildings in a large area; and various technologies for indoor positioning of other manufacturers such as Cisco, Aruba and Xirrus (Infsoft, 2016).

\subsection{IndoorAtlas}

Finnish company "IndoorAtlas Ltd." has built the IPS using geomagnetic technology. IPS includes a platform in the Cloud ${ }^{15}$ using geomagnetic technology in order to determine the position of a person located indoor (Sterling, 2014). In the process, magnetic fields are used to map the building, Wi-Fi infrastructure is required inside the building and an integrated compass on the smart device. It is stated on the company's Web portal that the data was very stable over time as opposed to RF ${ }^{16}$ signals with a Wi-Fi hot spot's or Bluetooth transmitters (Happich, 2016). The geomagnetic technology used has 1-2 meters accuracy (Happich, 2016). Other indoor positioning technologies use hardware components that need implementation and maintenance, while geomagnetic technologies do not require that.

The room should be mapped out first in a manner that a person who collects the data heads from a known point of departure and confirms the data collected at other points of space. The user that implements the IPS can create 2D maps even before the data is collected (Happich, 2016).

13 UWB (Ultra-wideband) is a short-range radio technology.

$14 \mathrm{SDK}$ (Software Development Kit) is a set of development tools required to build, test, and debug Android applications - URL: http://www.informatika.buzdo.com/pojmovi/mobile-4.htm

15 Cloud is the concept of the division of the programming environment that uses the Web as a platform, and allows applications and documents sent from anywhere in the world to be stored and kept at predetermined servers - URL http://security.lss.hr/arhiva-dokumenata/ cloud-computing.html

$16 \mathrm{RF}$ (Radio Frequency) is a measure of the rate of oscillation of electromagnetic waves - URL http://searchnetworking. techtarget.com/definition/radio-frequency 
It is used in airports in which the route and time required for the user to reach a certain output is determined, and provides research of facilities at the airport. Moreover, it is also used at various points of sale and has an advertising role (IndoorAtlas, 2017).

The system has been implemented at the Shinjuku, Shibuya and Tokyo metro stations. (GISuser, 2016).

The application of the IPS on the gaming platforms was also announced, so there is a possibility of playing "Pokemon Go" indoors in near future (Cardoza, 2016).

\subsection{Philips Lighting}

The Philips company produces household appliances, medical equipment, audio equipment and lighting. It consists of three divisions: "Philips Consumer Lifestyle", "Philips Healthcare" and "Philips Lighting" (Philips, 2017).

In Philips, it is considered that the lighting has already been installed in all indoor spaces and it is more natural to create a system for internal positioning out of a lighting system, than to install a completely separate infrastructure. Philips IPS system uses Philips VLC technology. With the help of VLC, each installation sends its unique ID to the user' smart device and the system can accurately determine the user's location in the store. VLC is installed directly in the Philips LED luminaires and does not require additional installation, maintenance or power. The luminaires provide all the benefits of the LED lighting, including high energy savings in relation to the classical lighting systems, and they also provide the infrastructure for service delivery for indoor positioning. In addition to LED lighting, the indoor positioning system comprises both IOS and Android SDK packages and cloud services.

The system does not require, collect nor store user data. Application users are logged in to the system anonymously (Philips, 2017-2).

The store in which Philips has installed its lighting is able to provide its customers with new services (help in getting around the store and finding a promotion) and reduce electricity consumption by 50\% (Afzal, 2015).

VLC lights in the store serve as a system for indoor locating. Each light bulb sends an identification code that is detected by the camera on a smart device and identifies the user's location. A mobile application submits this information to the user.

\section{TECHNOLOGIES FOR IPS}

The previous chapter has demonstrated the systems for indoor positioning. Each of them uses some types and combinations of technology. The technologies used in IPS systems will be now presented. 


\section{1 BLE}

Bluetooth technology is a wireless communication standard that is used to exchange data at a close distance. It was developed in 1994 by Ericsson, and in 1998 Ericsson, IBM, Intel, Nokia and Toshiba set up a special competent authority, the "Bluetooth Special Interest Group" (SIG). The role of the competent authority is to improve standards, proper implementation and licensing of Bluetooth technology.

The main features of Bluetooth technologyare low-cost Bluetooth devices, low power consumption, small range, robustness and global use. Bluetooth provides transfer speed of $1 \mathrm{Mbit} / \mathrm{s}$ and uses unlicensed frequency band of 2.4 to $2.485 \mathrm{GHz}$, that is, it uses ISM area (industrial, scientific and medical) where frequency is globally harmonized. Also, the Bluetooth offers a radio connection with other systems. Devices from different manufacturers are mutually incompatible, and packet and channel switching is allowed (Hamidović, 2009).

In mid-2010, the Bluetooth SIG announced the Bluetooth 4.0 specification, which included: Classic Bluetooth, Bluetooth high speed and Bluetooth low energy protocols.

Bluetooth low energy (BLE) is characterized by a very small size, low cost, low power consumption with the possibility of several years of work on a small power source (AAA batteries) and compatibility with mobile devices, tablets and computers.

To install the BLE technology in devices, Bluetooth 4.0 introduces two modes of operation: single-mode and dual-mode. Single-mode operation includes only the integration of the BLE functionality into the controller, while dual-mode operation allows the integration of BLE and Bluetooth functionality in the standard controller. Device manufacturers have these two options at their disposal and it is important to point out that devices with single-mode operation cannot communicate with devices that use classic Bluetooth protocol (Akiba et al., 2014).

Today, most mobile devices are produced with a support for standard Bluetooth and for the BLE, that is, a Bluetooth microcontroller with dual-mode operation is installed in devices. Mobile operating systems that currently support the BLE are: Android 4.3 and higher; iOS 5 and higher; Windows Phone 8.1; Blackberry 10 (Paganini, 2015).

The BLE broadcasts signals from transmitters that operate on batteries. The technology is available on most devices (smartphones, tablets). It uses the so-called beacon-e (transmitter) and location devices that are cheap, small in size, have a long battery life and do not require an external power source. The device detects the signal from the transmitter and can roughly calculate the distance to it and thus estimate the location of the device (Blaz, 2015).

Using the BLE technology, the transmitters notify the nearby devices on their presence. Nearby devices (mobile devices, tablets) can be subscribed to notifications of the transmitters and can receive a variety of content (such as text, images and $U R L$ ). At the same time, the transmitters can be used for contactless payments in a similar way as NFC ${ }^{17}$.

17 NFC (Near Field Communication) is a wireless technology that works on short distances - URL: http://mob.hr/sto-jei-kako-radi-nfc/ 
The lifespan of the transmitter is estimated at 5-8 years, transmitters are resistant to dust and water according to IP67 standard (Senion, 2017) and have a precision of 1-3 meters. (Infsoft, 2016.)

In order for the BLE technology to be used, it is necessary to turn on the Bluetooth or BLE.

The BLE transmitters have the ability to send notification to the user when the user is at a particular location (Mattsson, 2014).

\subsection{WPS (Wi-Fi positioning system)}

Wi-Fi is a technology that uses radio waves to connect to the network. Wi-Fi connection is established with the help of a wireless adapter which creates a wireless local area network in the vicinity of a wireless router, which is connected to the network and allows users to access Internet services. Once configured, Wi-Fi allows you to wirelessly connect to devices by emitting frequencies between $2.4 \mathrm{GHz}$ and $5 \mathrm{GHz}$ depending on the amount of data passing through the network (Aakai, 2016).

The term WPS originated from the Skyhook Wireless company which used the term to outline its Wi-Fi positioning system. Google, Apple, various phone manufacturers and phone operators have drawn up very extensive databases of Wi-Fi access points by connecting Wi-Fi access point with GPS locations of a smart device (Zahradnik, 2016). Anonymous determination of the user location is an integral part of any contract with a mobile operator. Most smart phones allow the user to turn off location services. A possibility to exempt a network form saving into the WPS base is supported by Google. It is necessary to add an extension "_nomap" to the name of the WiFi network and the network will not be mapped. WPS can be combined with a triangulation of repeaters of mobile operator and GPS in order to obtain reliable and accurate data on the position of users under a wide range of conditions, including passages between tall buildings and enclosed areas where GPS signals may be weak or intermittent. Disadvantages of WPS technology are the following: WPS does not work if the user is located outside the range of Wi-Fi signals, it is necessary to continuously update the database of Wi-Fi access points (Zahradnik, 2016).

Wi-Fi can be used in a similar way as the BLE transmitters, however, it requires an external power source, higher installation costs and more expensive equipment. Smart device need not be connected to a Wi-Fi network, but Wi-Fi connection needs to be enabled. The signal is stronger and can cover a longer distance than the BLE technology and the precision is 5-15 meters (Blaz, 2015).

There are several positioning techniques that use Wi-Fi technology. Triangulation is one of them. Triangulation uses the intersection of three circles of Wi-Fiaccess points in order to enable the exact position of the user. The triangulation collects signal strength of all existing Wi-Fi access points. The user's distance form a certain access points is calculated according to the signal strength, and thus, the exact position is obtained. The procedure is simple and easy to implement. Triangulation is also called dynamic positioning method (Palaskar et al., 2014). 
Another positioning technique using a wireless access network is based on measuring the intensity of the received RSSI ${ }^{18}$ signal and "fingerprinting" method. The MAC address of a device is also used. The application on the smart device of a user calculates the current position of the user based on the intensity of the received signal and the "fingerprinting" method (Gaudlitz, 2015).

The "fingerprinting" method consists of two phases: online and offline. In the offline training phase, the base of $\mathrm{RSS}^{19}$ data with the corresponding coordinates of the location is prepared. Data on the signal strength is collected from several different locations, and then stored in the database. This is the most important phase and the accuracy of locating depends on it. In the online phase, the user sends a query concerning the RSS data to the database, that is, known coordinates are compared with the unknown ones and the most accurate location is obtained Various examples of algorithms are used to find matching entries in the database with dynamic RSS. The most challenging task of the method is to design the RSS database of prints and its maintenance. Any addition, exclusion, or removal of furniture requires a reupdate of the database. The problem can be easily solved if another sensor is installed in the system - a camera (Palaskar et al., 2014).

\subsection{Geomagnetic technology}

The magnetic field detection can also be used for indoor positioning by using a compass sensor. The so-called "fingerprinting" method is used for mapping magnetic fields at a particular place after which a smart device can use the same map in order to find indoor locations. This technique can be applied only in certain circumstances, where the magnetic fields indoors are stable (Blaz, 2015). IndoorAtlas is currently the only company that implements this technology. It is stated that the distortion of magnetic fields in buildings due to material they are made of was ideal for magnetic imprint (Sterling, 2014). The more metal there is in the area, the imprint is more unique. It also said that the geomagnetic technology can be implemented in any indoor areas. Such a system does not require the installation of additional hardware. It is sufficient to pass through a room to collect data for magnetic positioning. The plan of the building is set on the cloud system and is connected with the magnetic imprints of the area. It takes about an hour to cover the 25,000 $\mathrm{m} 2$ of space (approximately 2,322 m2) in the accuracy of 1-2 meters. Non-technical staff members, any user, have also been enabled to generate magnetic imprint by using only their smart phone and instructions (Sterling, 2014).

\subsection{VLC}

Visual Light Communication (VLC) is a wireless technology that uses LED light as a communication channel. Just like Wi-Fi technology, the term Li-Fi technology derived thereof. It can be used as a standalone solution or as an addition to radio communication (Wi-Fi, mobile). The VLC operates in a way that the LED switches from ON to OFF state and vice versa at a high frequency (nano seconds) (Dilouie, 2014).

8 RSSI means Received Signal Strength Indication - URL: http://www.academia.edu/9895197/WLAN_Wi_Fi

19 RSS means Received Signal Strength. 
The LED sends a pattern of a blinking light received by a receiver, that is, a camera on a smart phone. The pattern is converted into an encrypted form and sent to the server. On the server, the encrypted form of the pattern is compared to the one on the map. When the identical encrypted form of the pattern is found on the map, the system implies that the user is positioned beneath the LED.

The downside of VLC technology is that the camera on the user's device has to have visual contact with the LED. The device will not receive notification if visual contact is not achieved, as opposed to the BLE technology transmitter that does not require the same. VLC determines the location very accurately, even up to $5 \mathrm{~cm}$.

\subsection{Other technologies}

Near Field Communication is a wireless technology that works on short distances and does not require a power source. A smart device will detect the NFC device and read the serial number if the device is located at a distance of $30 \mathrm{~cm}$. This technology is currently used in the system of sale, however, it can also be used for precise positioning indoors. The NFC technology is available on newer smart devices. The NFC could replace $\mathrm{QR}^{20}$ codes, as $\mathrm{QR}$ codes must be visible, they require a stronger lighting and a camera (Blaz, 2015).

The signal is reachable at the distance of up to 10 meters. The NFC can be used to increase the robustness of the IPS system that uses Bluetooth technology, since it is able to quickly connect to a smart device.

Radio Frequency Identification (RFID) is an automatic identification method by means of contactless communication techniques. NFC i RFID are relatively similar. Unlike the NFC, RFID technology cannot simultaneously send and receive data. Apple products still do not fully support this service (Infsoft, 2017).

The gyroscope is a device used for calculating the position, measuring and maintaining orientation. Most smart devices have built-in gyroscope and compass. A smart device can use this information as an addition to other technologies for more precise positioning (Blaz, 2015).

\section{ANALYSIS OF TECHNOLOGICAL CHARACTERISTICS OF IPS}

A more detailed explanation of certain categories of analysis is given below: location precision, battery life, maintenance, safety, installation costs, mapping method, the type of customer, push notifications and the "blue dot" navigation. The previously mentioned analysis categories represent the starting point for the selection of technologies for the IPS system implementation.

\section{1 Location precision}

The precision (accuracy) of locationing shows at what distances the indoor positioning is possible. The importance of the category depends on where the positioning system will be used. For

${ }^{20}$ QR (Quick Response) is a two-dimensional graphic code - URL: http://www.netokracija.com/qr-kod-8766 
example, if the user should be guided to a certain exit at the airport or to the doctor's office, the precision of 2 or 5 meters should not be a problem. If a person should be guided to a specific product or a group of products, greater precision will be needed.

\section{2 Battery life}

With regard to the analysed technologies, only BLE transmitters use battery and its lifespan depends on the model of the transmitter, battery type and settings, and it may last for more than two years.

The data on the cost of LED bulbs with VLC technology and the lifespan of a light bulb were not found in the source. The lifespan will depend on the wattage of a light bulb and estimated operating hours. If the light bulb has an estimated range of 50,000 operating hours, and if it is turned on 24 hours a day, the lifespan of a light bulb can be 5.7 years.

\section{3 Maintenance}

Maintenance may be analysed for BLE, Wi-Fi and VLC technologies since they are hardware components. Hardware components are not used in geomagnetic technology, so the maintenance may be more difficult to examine.

BLE technology requires skilled installers and constant calibration, depending on the changes in the observed area. Maintenance is made easier if management of the transmitters is centralized.

Given that the Wi-Fi infrastructure often already exists, maintenance of Wi-Fi technology for indoor positioning is facilitated. Current maintenance also includes the adjustment to changes in the environment and to infrastructure changes. This may be a malfunction of hardware or software, system upgrade or turning on or off of the access point if the router is controlled by a third party, e.g., the store owner at the mall (Luo et al, 2013).

The costs and maintenance of the VLC LED light bulbs are not significant. When the lifespan of the light bulb expires, it is replaced by a new one.

The hardware components may break down or be stolen, therefore, the replacement will be necessary. Wi-Fi and BLE transmitters are more exposed than the light bulbs.

\section{4 Safety}

The data on the user's location is a sensitive information that can present a problem if available or insufficiently protected. The level of system security can be explained by technical characteristics.

Client-based indoor positioning with BLE transmitters or via Wi-Fi system is generally safe. In such a system, the position is determined directly on the user' smart device without further communication with the server. The data are not forwarded further. BLE transmitters are not storage media for keeping users' personal information. They only contain certain key information such as the device $I D^{21}$ in order to gain access to and control the device.

${ }_{21}$ ID (Identifier) is a unique number used for identification 
When it comes to applications for anonymous tracking, smart device's UID ${ }^{22}$, BLE transmitter's UID, RSSI and timestamp ${ }^{23}$ are used and stored on the server. The smart device's MAC ${ }^{24}$ address is also retrieved. User information will not be transmitted if the user is registered anonymously.

The BLE transmitters are protected by a "rolling ID" method in order to prevent a third party from attempting to use them. Only the operator of the transmitter has the appropriate "key" to decode the transmitter. The transmitter's ID is changing, therefore it is necessary to use the system administration interface for a user (administrator) to be able to access the transmitter (Winkler, 2016).

The source states that the LED light bulbs with VLC technology are extremely safe, but there is no example and / or a detailed description mentioned. Philips respects the privacy of users in a way that the system is designed so that the user data are not required, collected nor stored. Application users are logged in to the system anonymously.

\section{5 Installation costs}

When it comes to magnetic technology, the installation of the device is not needed, so there are no installation costs.

Regarding the VLC technology, costs can be high if all current luminaires are replaced. In terms of initial installation, the costs are not that high since there is also a need for the installation of luminaires. The price of a LED light bulb using VLC technology should be compared to a price of a normal light bulb in order to estimate the installation costs.

For Wi-Fi, installation costs are not high if one intends to use the existing infrastructure, or at least a part of it. If, however, access points are introduced only for those purposes, costs of devices and installations are observed as the cost of installation.

Depending on the model, strength and settings, the price of BLE transmitter ranges from 5-30 dollars for a piece (Martin, 2016). The unit price of the device is not high, but when it comes to IPS modelling, transmitter location will be defined, so, considering the quantity, the total cost of installation can be high.

\subsection{Mapping method}

Mapping a certain area in order to implement IPS. For Wi-Fi and VLC technology, it is necessary to map the area where the system will be installed and, if necessary, the system will be re-calibrated. In terms of BLE technology, similar procedures are carried out and applications for managing all devices are used.

${ }_{22}$ UID (Unique Identifier) is a unique number used for identification- URL: http://internetofthingsagenda.techtarget. com/definition/unique-identifier-UID

23 Timestamp is the time of an event recorded by a computer - URL: http://whatis.techtarget.com/definition/ timestamp

${ }^{24}$ MAC (Media Access Control) is a unique identifier that is found in almost all network devices - URL: http://www. sveznadar.info/20-WINTipsTricks/11-MrezaRazniPojmovi/12-1-Pojmovnik-MAC.html 
When it comes to magnetic technology, users can independently collect data on magnetic fields which are then submitted to the manufacturer of the IPS. The data is then processed and made available for use. A user can introduce any change in the same way. The cost of such a technique of mapping area is not significant since it does not require field work of professional staff in order to map the area. Waze ${ }^{25}$ uses similar technique (Starling, 2014).

\subsection{Client types}

The client types are Android and iOS users. All technologies, apart from Wi-Fi-based IPS systems, can be used by both types of clients, while the above mentioned system can be used only by Android users. Devices with iOS 4.3 (since March 2011) and above no longer support positioning via Wi-Fi technology on the client (Gaudlitz, 2016). In its announcement of iOS 8, Apple introduced its indoor positioning location service integrated into the operating system. Using the motion sensor, Wi-Fi and iBeacon technology devices can detect when the user is located in the room and start determining the location. The technology will also be used in public places where Apple would be able to introduce the service in cooperation with building owners. The service will not be available to Android users (McGlynn, 2014).

\section{8 Push notifications}

Push notifications ${ }^{26}$ are only enabled using BLE technology.

\subsection{Blue dot navigation}

During indoor navigation, the user's position is continuously monitored and a blue dot is visible on the screen of the smartphone. The blue dot shifts depending on the movement of the user. This term became known as the blue dot experience when the dot on the screen moves in accordance with the user.

BLE technology can support real-time monitoring with the help of certain algorithms and densely distributed BLE transmitter. The blue dot experience is not possible if there is not a sufficient number of BLE transmitters in the building. When using BLE technology, the blue dot experience is usually achieved in combination with another technology. There is such a solution (although limited). Estimote Indoor Location system can provide visualization of a user approximate position within space in a real-time (Estimote, 2017). Estimote beacons need to be set up on the center of each of the walls. By walking near the beacons user is mapping the area and configuring the beacons. Once complete, the user location is automatically saved in Estimote Cloud, and the user can use their SDK to see real-time user positions within that space. (Estimote, 2017).

25 Waze is one of the larger community-based traffic and navigation application in which users share real-time traffic and road information - URL: https://waze.com.hr/o-waze-aplikaciji/detaljnije-o-aplikaciji/

26 Push notification is a delivery of information from software applications to computing device without a specific request from the recipient (client) - URL: http://www.mojatvrtka.hr/sto-su-push-notifikacije/ 


\section{10 Signal chane sensitivity}

BLE technology, when used for IPS is sensitive on the changing radio conditions. Just the presence of humans in the room can change drastically the signal perception in different positions in the room. For this reason to obtain good localization and signal perception when installing the beacons the line of sight is sought when possible between the receiver and the beacon, typically placing the beacons above head height (Steczkiewicz, 2015).

Various surfaces can cause interference with Bluetooth signals, including glass and metal. Additional beacons can be used to counter any interference in the room (Estimote, 2017).

Wi-fi signal can also be blocked by household electronics, bluetooth devices, physical barriers or humans (Bertolucci, 2011).

Indoor magnetic field contains location information but this information is interfered in by hard/ soft-iron effect, hand quiver, and electronic noise. These interferences decrease the distinguishability of location fingerprints in magnetic field based localization systems (Wenhua Shao et al., 2016.)

VLC technology is sensitive in a sense that everything that interferes with visual line of sight of LED light is directly interfering in functioning of the indoor positioning technology.

\section{DISCUSSION OF THE ANALYSIS RESULTS}

Table 1 shows aggregated data of the analysis of the technologies for IPS.

Table 1. Technologies and their features

\begin{tabular}{|l|l|l|l|l|}
\hline & \multicolumn{1}{|c|}{ BLE } & \multicolumn{1}{c|}{ Wi-Fi } & \multicolumn{1}{c|}{ Magnetic } & \multicolumn{1}{c|}{ VLC } \\
\hline Location precision & $2 \mathrm{~m}$ & $5 \mathrm{~m}$ & $2 \mathrm{~m}$ & $\mathbf{5 m}$ \\
\hline Battery life & $5-8$ years & No & No & 5,7 years/0-24h \\
\hline Maintenance & average & average & Easy & Easy \\
\hline Safety & high** & average & High & High \\
\hline Installation costs & Average & High & Low & Average \\
\hline Mapping method & $\begin{array}{l}\text { Device } \\
\text { management }\end{array}$ & $\begin{array}{l}\text { Mapping/ } \\
\text { fingerprinting }\end{array}$ & Environment & Mapping \\
\hline Programming environment & Android/iOS & Android* & Android/iOS & Android/iOS \\
\hline Push notifications & Supported & Not supported & Not supported & Not supported \\
\hline Blue dot navigation & Supported & Supported & Supported & Supported \\
\hline Signal change sensitivity & Sensitive & Sensitive & Sensitive & Sensitive \\
\hline $\begin{array}{l}\text { *iOS does not support Wi-Fi scanning } \\
\text { **Technology features with an advantage in relation to another under a certain entry are marked in bold }\end{array}$ \\
\hline
\end{tabular}

Source: authors

The precision of locating is highest when it comes to VLC technology with accuracy of 5 $\mathrm{cm}$. 
Regarding the battery life, the highest efficiency was observed in the best technologies that actually did not use batteries, and those were $\mathrm{Wi}$-Fi and geomagnetic technologies.

Geomagnetic technology is the easiest one to maintain since it does not require any hardware, so updating the map is very easy and it can be performed by a user with the help of instructions. VLC technology is integrated into the LED lighting which needs to be regularly maintained, depending on the longevity of the light bulb.

Security is very high when it comes to BLE, magnetic and VLC technology, as explained in details above.

The installation costs are the lowest for geomagnetic technology since it does not require any installation of hardware.

The best mapping is observed with geomagnetic technology since it can be done by an ordinary user and professional knowledge is not required.

As far as the platform is concerned, all technologies support iOS and Android operating systems, except for Wi-Fi technology which is not supported in iOS 4.3 and higher. Apple eliminates this possibility and develops its own system of indoor positioning that will be enabled only to iOS users.

Push notifications are supported only by BLE technologies and this is also why BLE technologies are used in combination with some other technologies. Combining technologies could give some functionalities of the IPS that would not be possible if technologies were being used separately.

Blue dot navigation is supported on all researched technologies.

The signal change sensitivity was also researched and all of the technologies had the same problem. They all had some possibilities of interferences, e.g. some objects, humans, another technology with the same radio signal.

Companies that want to implement indoor positioning should clearly define their needs. It is not possible to say that one technology is the best for using in the IPS. If during an implementation in the IPS individual technologies are combined, better IPS features can be achieved due to their individual characteristics. Thus, for example, VLC or geomagnetic technology may be combined with BLE technology. Wi-Fi is not a good choice of technology for IPS since it is not supported in iOS, and it is not basically designed for indoor locationing.

Aspects of every explained category is important. Companies should know their needs and depending on them they have to choose the best suited technology. For example, hospitals or airports do not need a very high accuracy like supermarkets so they can achieve indoor positioning system by simply implementing BLE technology. On the other hand, supermarkets do need high precision but also need push notifications to share their marketing ideas so they should use a combination of technologies like VLC and BLE. In the 
long run, companies should consider thefrequency of changing batteries, or a possibility of stealing a technology. Also, the should cosider the following: how easy it is to maintain the system, could current personnel maintain it or should the company have additional cost of maintaining the system by associates (developer). Also, how safe is the system for the company and its users.

Considering all these characteristics, the BLE technology as an indoor positioning technology individually achieves the most favourable results.

\section{CONCLUSION}

Certain technologies used in the indoor positioning system have been presented in the paper. The very concept of the indoor positioning is quite new and it is difficult to say that one technology presents a standard. This domain is still being researched and such systems are reaching their market.

We have described IPS, its characteristics and its basic technologies. We have analysed technological characteristics of IPS on a few IPS examples.

Results of the analyses shows that none of the analysed technologies achieve the best results according to all analysed characteristics, but BLE technology is the most favourable one. BLE technology individually achieves the most favourable results. Also, the Wi-Fi technology achieves the most unfavourable results.

In the implementation of an IPS, a company should choose a certain technology on the basis of the preferred functions of the system, the type of building where the technology will be implemented in and its available budget.

IPS technology standard still does not exist. Eventually, one of the existing technologies, a combination of these technologies, or even a new technology can become a standard.

\section{REFERENCES}

AAkai (2016) "What is WiFi and How Does it Work?", 2016., http://ccm.net/faq/298-what-is-wifi-and-how-does-it-work (23.01.2017.)

Afzal, S. (2015) “Philips News: Where are the discounts? Carrefour's LED supermarket lighting from Philips will guide you”, 2015., http://www.philips.com/a-w/about/news/archive/standard/news/press/2015/20150521-Where-are-thediscounts-Carrefours-LED-supermarket-lighting-from-Philips-will-guide-you.html (3.01.2017.)

Akiba, Cufi, C., Davidson, R., Townsend, K. (2014) "Getting Started with Bluetooth Low Energy", 2014., https://www. safaribooksonline.com/library/view/getting-started-with/9781491900550/ch01.html (23.01.2017.)

Allan, A. (2015) “Eddystone”, 2015., http://makezine.com/2015/07/20/google-introduces-eddystone-beacon/ (23.01.2017.)

Bertolucci, J. (2011) “Six Things That Block Your Wi-Fi, and How to Fix Them”, 16.05.2011., http://www.pcworld.com/ article/227973/six_things_that_block_your_wifi_and_how_to_fix_them.html (13.03.2017.) 
Blaz, (2015) “Indoor Positioning Systems based on BLE Beacons - Basics”, 2015., https://locatify.com/blog/indoor-positioningsystems-ble-beacons/ (01.01.2017.)

Bronzin, T.(2009) "Cloud Computing ili programska rješenja u oblacima”, 29.08.2009., https://pogledkrozprozor.wordpress. com/2009/08/29/\%E2\%80\%9Ecloud-computing\%E2\%80\%9C-ili-programska-rjesenja-u-oblacima/ (01.02.2017.)

Cardoza, C. (2016) "Ensuring Pokémon Go is a mobile success", 2016., http://sdtimes.com/ensuring-pokemon-go-mobilesuccess/ (03.01.2017.)

Dilouie, C. (2014) “Visible Light Communication”, 2014., http://lightingcontrolsassociation.org/content/whitepapers/visiblelight-communication/ (03.01.2017.)

Estimote (2017) “Estimote Indoor Location”, 2017., https://estimote.com/indoor/ (13.03.2017.)

Gaudlitz, E. (2016) “Indoor navigation with Android and iOS devices - what are the differences and fields of application?", 2016., https://www.infsoft.com/blog-en/articleid/55/indoor-navigation-with-android-and-ios-devices-what-are-thedifferences-and-fields-of-application (04.01.2017.)

Gaudlitz, E.(2015) "Indoor navigation using WiFi as a positioning technology", 2015., https://www.infsoft.com/blog-en/ articleid/40/indoor-navigation-using-wifi-as-a-positioning-technology (03.01.2017.)

GISuser (2016) "Yahoo! JAPAN just updated their "Yahoo! Maps" application with more Indoor Maps", 10.06.2016., http:// gisuser.com/2016/06/yahoo-japan-just-updated-their-yahoo-maps-application-with-more-indoor-maps/ (01.02.2017.)

Gottipati, H. (2013) “With iBeacon, Apple is going to dump on NFC and embrace the Internet of things", 2013., https://gigaom. com/2013/09/10/with-ibeacon-apple-is-going-to-dump-on-nfc-and-embrace-the-internet-of-things/ (23.012017.)

Hamidović, H. (2009) “WLAN - Bežične lokalne računalne mreže”, 2009., https://goo.gl/Chc3LH (23.01.2017.)

Happich, J. (2016) "Big in Japan! Geomagnetic indoor positioning", 2016., http://www.electronics-eetimes.com/news/bigjapan-geomagnetic-indoor-positioning/page/0/2 (03.01.2017.)

Haverinen, J. "Yahoo! JAPAN Goes Live With Indoor Location Finding And Route Navigation To Yahoo! Maps Users”, 2016. http://www.indooratlas.com/2016/06/09/yahoo-japan-goes-live/ (03.01.2017.)

IndoorAtlas (2017) “Use cases”, 2017., http://www.indooratlas.com/use-cases/ (05.02.2017.)

Infsoft (2016) “Indoor Positioning”, 2016., https://www.infsoft.com/indoor-positioning (29. studeni 2016.)

Infsoft (2017) “NFC (Near Field Communication)”, 2017., http://www.indoornavigation.com/wiki-en/nfc-near-fieldcommunication (23.01.2017.)

Krajačić, N. (2011) “QR kod možete očitati s reklama te web stranica, ali i stvoriti vlastiti”, 18.03.2011., http://www.netokracija. com/qr-kod-8766 (01.02.2017.)

Lee, K. (2012) “Finally: Indoor GPS System Uses Your Smartphone and Earth's Magnetic Field”, 2012., http://www.pcworld. com/article/258961/finally_indoor_gps_system_uses_your_smartphone_and_earth_s_magnetic_field.html (03.01.2017.)

Lemmens, M. (2013) "Indoor Positioning", 28.10.2013., https://www.gim-international.com/content/article/indoorpositioning-2 (01.01.2017.)

Lifeware (2016) “Wi-Fi Positioning System”, 2016., https://www.lifewire.com/wifi-positioning-system-1683343 (23.01.2017.)

Luo, Y., Hoeber, O., Chen Y. (2013) “Enhancing Wi-Fi fingerprinting for indoor positioning using human-centric collaborative feedback”, 2013., https://hcis-journal.springeropen.com/articles/10.1186/2192-1962-3-2 (04.01.2017.)

Martin, A., J. (2016) "6 things marketers need to know about beacons", 24.02.2016., http://www.cio.com/article/3037354/ marketing/6-things-marketers-need-to-know-about-beacons.html (02.02.2017.)

Mattsson, J. (2014) “What's Needed? -- Key Indoor Location Technology for Airports \& Retail”, 2014., http://www.walkbase. com/blog/what-is-needed-key-indoor-location-technology-for-airports-and-retail, (23.01.2017.)

McGlynn, P. (2014) “The Guide To Indoor Location Services”, 2014., https://bluefletch.com/blog/the-guide-to-indoorlocation-services/ (23.01.2017.) 
Meridian (2017) "Providing Indoor Location in the Real World", 2017., http://meridianapps.com/news/2015/12/02/indoor/ (13.03.2017.)

Paganini, P. (2015) "Tracking wearable devices could be very easy via Bluetooth Low Energy", 2015., http://securityaffairs.co/ wordpress/37149/hacking/tracking-bluetooth-low-energy-devices.html (23.01.2017.)

Palaskar, P., Pathak, O., Palkar, R., Tawari, M. (2014) “Wi-Fi Indoor Positioning System Based on RSSI Measurements from Wi-Fi Access Points - A Tri-lateration Approach", 2014., http://www.ijser.org/researchpaper/Wi-Fi-Indoor-Positioning-SystemBased-on-RSSI-Measurements.pdf(23.01.2017.)

Philips (2017) “Company Introduction”, 2017., http://www.philips.com/a-w/about/company/introduction.html (03.01.2017.)

Philips (2017-2) “LED based indoor positioning”, 2017., http://www.lighting.philips.com/main/systems/themes/led-basedindoor-positioning.htm|\#form_white_paper (03.01.2017.)

Senion (2015) "Westfield San Fransisco Centre", 2015., https://www.youtube.com/watch?v=WSJnkDZ4lyU\&t=101s (21.01.2017.)

Senion (2015-2) “Westfield Valley Fair", 2015., https://www.youtube.com/watch?v=wHCeBJOyzll\&t=107s (21.01.2017.)

Senion (2015-3) “Mandalay Bay in Las Vegas", 2015., https://www.youtube.com/watch?v=JfPAlodjauE\&t=22s (21.01.2017.)

Senion (2015-4) https://senion.com/press/senionlab-launches-stepinside-industrys-most-powerful-indoor-positioningsystem-suite/ (01.02.2017.)

Senion (2016) “Indoor Positioning System”, 2016., https://senion.com/indoor-positioning-system/ (29.10.2016.)

Senion (2017) “Senion", 2017., https://senion.com/ (05.02.2017.)

Senion (2017-2) “Products and services”, 2017., https://senion.com/products-services/ (05.02.2017.)

Senion (2017-3) “IPS”, 2017., http://innovation.mubaloo.com/senion-lab/ (02.01.2017.)

Steczkiewicz, A. (2015) “Best practices for installing Estimote Beacons", 03.12.2015., https://community.estimote.com/hc/enus/articles/202041266-Best-practices-for-installing-Estimote-Beacons (13.03.2017.)

Sterling, G. (2014) "Magnetic Positioning: The Arrival of Indoor GPS", 2014., http://www.indooratlas.com/wp-content/ uploads/2016/03/magnetic_positioning_opus_jun2014.pdf (04.01.2017.)

Törnqvist, D. (2015) “Proximity vs true location”, 2015., https://senion.com/insights/point-positioning-vs-true-location/ (22.01.2017.)

Zahradnik, F. (2016) “Wi-Fi Positioning System”, 14.09.2016., https://www.lifewire.com/wifi-positioning-system-1683343 (1.02.2017.)

Wenhua Shao et al. (2016) "Location Fingerprint Extraction for Magnetic Field Magnitude Based Indoor Positioning", 30.10.2016., https://www.hindawi.com/journals/js/2016/1945695/ (13.03.2017.) 


\section{ANALIZA SUSTAVA ZA UNUTARNJE LOCIRANJE ${ }^{4}$}

\section{SAŽETAK}

Zbog napretka u razvoju raznih tehnologija koje se mogu koristiti za lociranje, u posljednje vrijeme razvijaju se sustavi koji uključuju programska rješenja za lociranje i navođenje korisnika u unutarnjem, zatvorenom ili natkrivenom prostoru, gdje se postojeće tehnologije za lociranje i sustavi za lociranje i navođenje koje se primjenjuju kod otvorenih, vanjskih prostora, ne mogu koristiti. U radu se analiziraju dostupne hardverske, softverske i mrežne tehnologije kojima je moguće izraditi sustav za unutarnje lociranje, odnosno tehnologije kojima takav distribuirani sustav po svom karakteru i implementiranim funkcijama postaje sustav za lociranje u zatvorenom prostoru (IPS, engl. Indoor Positioning System). Opisan je koncept IPS sustava. Prikazani su gotovi IPS sustavi dostupni na tržištu. Pokazane su tehnologije koje se mogu koristiti za implementaciju IPS-a i izrađena analiza kategorija koje utječu na implementaciju IPS-a. Pokazano je da niti jedna tehnologija ne zadovoljava sve promatrane kategorije, no BLE tehnologija omogućuje ostvarenje najpovoljnijih rezultata po pojedinim kategorijama.

Ključne riječi: IPS, unutarnje lociranje

Dr. sc., viši predavač, Veleučilište u Rijeci, Vukovarska 58, 51000 Rijeka, Hrvatska.E-mail: mkaluza@veleri.hr Studentica, Veleučilište u Rijeci, Vukovarska 58, 51000 Rijeka, Hrvatska.E-mail: kbeg@veleri.hr Mr. sc., viši predavač, Veleučilište u Rijeci, Vukovarska 58, 51000 Rijeka, Hrvatska.E-mail: bvukelic@veleri.hr Datum primitka rada: 15. 2. 2017.; datum prihvaćanja rada: 1. 4. 2017. 